\title{
Euthanasia: agreeing to disagree?
}

\author{
Søren Holm
}

Published online: 31 July 2010

(c) The Author(s) 2010. This article is published with open access at Springerlink.com

\begin{abstract}
In discussions about the legalisation of active, voluntary euthanasia it is sometimes claimed that what should happen in a liberal society is that the two sides in the debate "agree to disagree". This paper explores what is entailed by agreeing to disagree and shows that this is considerably more complicated than what is usually believed to be the case. Agreeing to disagree is philosophically problematic and will often lead to an unstable compromise.
\end{abstract}

Keywords Agree to disagree - Conscientious objection . Euthanasia $\cdot$ Liberalism $\cdot$ Public policy

In discussions about the legalisation of active, voluntary euthanasia performed by medical doctors ${ }^{1}$ it is sometimes claimed that what should happen in a liberal society is (merely?) that the two sides in the debate "agree to disagree" or "split the difference" (Huxtable 2007); and the Netherlands is taken as an example of this kind of accommodation. Agreeing to disagree will allow persons to pursue their own idea of the good life and the good death both as patients and as health care professionals, it will calm the often vociferous and unnecessarily antagonistic public debate, it will exhibit state impartiality and it will lead to a resolution that is the right one in an area where significant liberty interests of patients are at stake.

\section{S. Holm ( $\square)$}

Centre for Social Ethics and Policy, School of Law,

Williamson Building, University of Manchester,

Manchester M13 9PL, UK

e-mail: Soren.holm@manchester.ac.uk

\section{S. Holm}

Section for Medical Ethics, University of Oslo, Oslo, Norway
The underlying idea is that even if we cannot agree on whether euthanasia is ethically acceptable we can reach a societal accommodation that allows those who can find a willing doctor to end their life by euthanasia without fear of criminal prosecution.

The present paper will problematise this account of the virtues and effects of "agreeing to disagree" through an analysis of what that type of societal accommodation actually entails in the context of euthanasia.

The first part of the paper will briefly rehearse some philosophical arguments against compromise or accommodation as a viable option in a context of deep value conflict about an important ethical issue.

The second part will then more concretely analyse (1) what the pro-euthanasia side wants to achieve by the legalisation of euthanasia and (2) what the anti-euthanasia side is worried about in relation to legalisation.

The third part will then show that "agreeing to disagree" is significantly more complicated and fraught with problems than is sometimes assumed.

Throughout the paper no position will be taken as to whether euthanasia is in general, or in specific instances ethically justifiable. The analysis will primarily be drawing on resources from political philosophy and political science and not from moral philosophy.

The paper will also not try to provide a final answer to the question of whether "agreeing to disagree" is a philosophically coherent position to advocate given the strong underlying views on both sides of the debate. But it is worth noting that for someone, such as Dame Mary Warnock believes that doctors who refuse euthanasia requests are 'Genuinely wicked' it would be strange to

\footnotetext{
${ }^{1}$ In the following all unqualified uses of the term "euthanasia" refer to active, voluntary euthanasia performed by a doctor.
} 
agree to disagree and difficult to see what the agreement could be about (News Letter 2009).

\section{Agreeing to disagree and deep value conflict}

Within a modern liberal society it is arguable that the best way of resolving policy differences is through some form of deliberative democracy. The parties sit down, trash out their differences and try to argue their way to an outcome that is either accepted or at least acceptable to all participants in the process (Guttman and Thompson 1990; Guttman 1993; Habermas 1992; Habermas 1995; Rawls 1996; Holm 2006).

At both the theoretical and the practical level this kind of process is likely to work best when the different views of the parties stem only from the fact that they have different interests. Such differences can be mediated through reflection and/or compromise.

If, however the differences are differences in values it may be more difficult to achieve a resolution or a compromise. Values are often more intimately connected with the participant's ultimate world view than interests are and they more often involve metaphysical commitments (McCarthy 1996). ${ }^{2}$ This is, for instance quite obvious in the abortion debate where one of the issues at stake is the metaphysics of persons and of personal identity.

There are circumstances where disagreements about values are likely to generate irresolvable standoffs. This is especially likely to happen if one or both of the positions involve what John Woods calls:

“Philosophy's Most Difficult Problem. Let $A=$ $<\{P 1, \ldots, P n\}, C>$ be a valid argument, a sequence in which $C$ is a logical consequence of proceeding steps. Philosophy's Most Difficult Problem is that of adjudicating in a principled way the conflict between supposing that $A$ is a sound demonstration of a counterintuitive truth, as opposed to seeing it as a counterexample of its premises." (Woods 2000, p. 205).

Discussions about euthanasia often involve exactly this kind of problem. It is, for instance well known that the personhood approaches to moral status involved in many pro-euthanasia arguments generate highly counterintuitive results in relation to beginning of life and end of life issues

\footnotetext{
${ }^{2}$ Let us in passing note that any call for the exclusion of metaphysical commitments from ethical debates about human life and death is potentially highly problematic. First because every participant in the debate has metaphysical commitments that influences their position and second because the exclusion of metaphysical commitments from the debate is likely to be a bigger burden for some participants than for others.
}

and that these very results are often seen as a reductio of such approaches by their opponents.

If, furthermore the values on both sides are firmly entrenched we may reach a standoff that excludes negotiability, where the mere suggestion that there is a possible compromise is seen as grotesque and improper.

\section{What is the legalisation of euthanasia supposed to achieve?}

Let us, despite the philosophical problems raised above move on and ask what proponents of euthanasia want to achieve through the legalisation of the activity.

The most minimal legalisation of euthanasia would simply involve the decriminalisation of the activity, but supporters of euthanasia understandably want more, because mere decriminalisation will not in itself entail that euthanasia is available.

Decriminalisation is, for instance, compatible with strong professional condemnation and disciplinary action and even with expulsion from the profession of those who perform the acts. The UK regulator of medical doctors the General Medical Council (GMC) does, for instance, oblige doctors to observe duties that they are not legally obliged to observe (e.g. acting as good Samaritans) and it requires them to abstain from acts that are not illegal (e.g. looking at legal internet pornography on work computers). Doctors who breach GMC guidance in these areas may lose their license to practice, even if they have done nothing that could remotely be construed as illegal or criminal. Supporters of euthanasia will therefore not only require that euthanasia is decriminalised but also that it is deemed to be acceptable professional practice and are furthermore likely to require that those who choose to practise euthanasia within the agreed boundaries are not discriminated against in employment decisions.

This is part of a more general feature of the pro-euthanasia position. Those who hold this position view euthanasia as morally justified and therefore also want it to become socially normalised. For them euthanasia is just a normal medical service; and in public health care systems or systems with a large component of third party payment supporters of euthanasia will also want euthanasia to be conceived of as a normal health care service in relation to payment. For instance, if a General Practitioner (GP) attends a patient at home to perform euthanasia the GP should be reimbursed as for any other home visit of similar complexity.

The requirement of normalisation of euthanasia also reaches beyond the health care setting to issues such as death certification, burial and insurance law. For the proponent of euthanasia, death following euthanasia should be 
treated as a 'normal death' and not for instance as a kind of suicide or a potentially illegal killing. ${ }^{3}$

\section{What worries does legalisation of euthanasia raise?}

Opponents of euthanasia share the concern about the effect of legalisation on the status of health care professionals, but they are likely to focus on the other side of the coin, i.e. the effects in relation to those who do not want to perform euthanasia. Any euthanasia legislation is likely to contain a conscientious objection provision, but this may not be enough to protect doctors and other health care professionals in the long run. After the legalisation of abortion it has become difficult for doctors who do not want to perform abortions to specialise in gynaecology and obstetrics and similar difficulties might occur in some specialties in relation to euthanasia. There has also been a tendency in some jurisdictions to interpret conscientious objection clauses quite narrowly both with regard to the type of health care personnel that is covered and with regard to the kind of involvement that a person can object to participate in. Opponents of euthanasia are therefore likely to require stronger protections than mere conscientious objection.

A related issue is that a right to conscientious objection is often combined with a professional duty to refer the patient to another practitioner willing to perform the act in question. But for someone who thinks that euthanasia is closely akin to murder such a duty is highly problematic.

More generally those who are opposed to euthanasia will also be opposed to the general normalisation of euthanasia as a medical service. They are likely to want it to be kept separate and special, and may be unlikely to be willing to have it included in normal reimbursement mechanisms. This may be combined with an unwillingness to contribute financially through insurance premiums or taxation to a practice seen as morally abhorrent.

In relation to resources in the health care system there may also be a worry about whether introducing euthanasia as an option undermines or weakens claims to have expensive life prolonging treatment provided, or whether in the long run a presumption would be established that choosing euthanasia was the morally right choice in some circumstances of severe resource constraints.

Opponents of euthanasia are also likely to have a distinct worry in relation to whether both sides involved in the societal bargain are willing to let it stand. Is "agreeing to disagree" about active, voluntary euthanasia performed by a medical doctor a stable accommodation or just a staging

\footnotetext{
3 This is exactly why the "Dutch solution", leaving euthanasia as technically illegal but not prosecuted if the criteria are fulfilled is often criticised by proponents of euthanasia.
}

post to the legalisation of other forms of euthanasia. This is, paradoxically a concern that is at least partially fuelled by the writings of academic bioethicists and legal scholars in relation to end of life decisions and abortion. A typical type of argument in these writings is a consistency argument of the form "society already allows $\mathrm{X}$, therefore it is inconsistent not to allow Y which is currently prohibited". There are many problems with consistency arguments of this type, but they are never the less often rhetorically powerful (Holm 2003). It is obvious that the legalisation of euthanasia will enable a variety of new consistency arguments to be brought forward. What is going to be legalised is, for instance not initially "euthanasia on demand" but euthanasia in cases of terminal disease with significant, irremediable suffering. But the underlying justification for allowing euthanasia only in this specific class of circumstances is inherently unstable because it relies on elements of both respect for autonomy and the relief of suffering.

\section{Why is agreeing to disagree difficult?}

From the analysis so far it has become clear that there are several problems with implementing "agreeing to disagree" as a societal accommodation or compromise in relation to euthanasia, even if we believed it made philosophical sense to advocate such a position.

The first problem is that whereas it might be possible to agree to disagree about the very narrow issue of decriminalisation of euthanasia, it is much more difficult to agree to disagree about the normalisation of euthanasia as a type of medical/health care intervention. It is practically difficult to confine the legalisation of euthanasia to mere permission. There will almost always also be an element of acceptance in any legalisation. ${ }^{4}$

The second problem is that the situation established by agreeing to disagree is unstable. It satisfies neither side in the debate and there is therefore always a temptation to try to disturb the equilibrium and get a little more; and a possible lingering suspicion that that is exactly what the other side will try to do.

The third problem is that any move from the now prevailing status quo in most countries, i.e. that euthanasia is illegal will be a move that only involves loss seen from the point of view of a strict opponent of euthanasia. For such and opponent there is nothing to be gained in the move itself and the only incentive to agree to disagree is if it is

\footnotetext{
${ }^{4}$ Even mere decriminalisation of euthanasia by medical doctors could be seen as conveying some form of social acceptance by classifying the act as a medical act and thereby lending it some of the lustre (if such lustre exists) of medicine and the medical profession.
} 
believed that the legal position after agreeing to disagree will be more restrictive than any position that would be reached without agreeing to this form of accommodation.

If the position in the Netherlands can rightly be described as "agreeing to disagree", and I do not want to claim that this is an accurate or adequate description, then it is a position that has been reached through a long historical development. It has been reached in a specific societal context and there is evidence that what the Dutch have agreed to disagree about has changed over time. It is not obvious that other societies can reach the same kind of accommodation in one single step.

For the philosopher the main problem with "agreeing to disagree" as a policy solution is that it requires both sides to suspend judgement on whether the counterintuitive consequences of accepting, for instance a personhood based justification of the permissibility of voluntary, active euthanasia should count as a reductio or should instead be seen as pointing to future goals for policy development. It furthermore requires the philosophical proponents of euthanasia to acquiesce in what they see as illiberal legislation prohibiting euthanasia in circumstances where it should be allowed; and it requires the philosophical opponents of euthanasia to accept that a kind of killing they think is profoundly unethical should be allowed in law. We can see how philosophers on both sides might "agree to disagree" as citizens, but if they continue to believe, as they almost inevitably must do that they have the correct argument on their side, agreeing to disagree will create significant cognitive dissonance and unease.

Open Access This article is distributed under the terms of the Creative Commons Attribution Noncommercial License which permits any noncommercial use, distribution, and reproduction in any medium, provided the original author(s) and source are credited.

\section{References}

Doctors who refuse euthanasia 'wicked', expert claims. News Letter, 06.01.2009 http://www.newsletter.co.uk/news/Ignoring-a-deathwish-is.4845993.jp.

Guttman, Amy. 1993. Democracy. In A companion to contemporary political philosophy, ed. R.E. Goodin, and P. Pettit, 411-421. Oxford: Blackwell.

Guttman, Amy, and Denis Thompson. 1990. Moral conflict and political consensus. Ethics 101: 64-88.

Habermas, Jürgen. 1992. Faktizität und Geltung. Frankfurt am Main: Suhrkamp.

Habermas, Jürgen. 1995. Reconciliation through the public use of reasons: Remarks on John Rawls's political liberalism. Journal of Philosophy 92: 109-131.

Holm, Søren. 2003. "Parity of Reasoning" arguments in bioethicssome methodological considerations. In Scratching the surface of bioethics, eds M. Häyry, T. Takala, 47-56, Amsterdam: Rodopi.

Holm, Søren. 2006. Policy making in pluralistic society. In Oxford handbook of bioethics, ed. B. Steinbock, 153-174. Oxford: Oxford University Press.

Huxtable, Richard. 2007. Euthanasia, ethics and the law-from conflict to compromise. London: Routledge-Cavendish.

McCarthy, Thomas. 1996. Legitimacy and diversity: Dialectical reflections on analytical distinctions. Cardozo Law Review 17: $1083-1125$.

News Letter. 2009. Doctors who refuse euthanasia 'wicked', expert claims. http://www.newsletter.co.uk/news/Ignoring-a-deathwish-is.4845993.jp Accessed 12 May 2010.

Rawls, John. 1996. Political liberalism (with a new introduction and the "reply to Habermas"). New York: Columbia University Press.

Woods, John. 2000. Privatizing death: Metaphysical discouragements of ethical thinking. Midwest Studies in Philosophy 24: 199-218. 